\title{
Introduction to the Minitrack on Streaming Media in Entertainment
}

\author{
Franziska Zimmer \\ Heinrich Heine University \\ Düsseldorf \\ franziska.zimmer@hhu.de
}

\author{
Katrin Scheibe \\ Heinrich Heine University \\ Düsseldorf \\ katrin.scheibe@hhu.de
}

\author{
Maria Törhönen \\ Tampere University \\ maria.torhonen@tuni.fi
}

\author{
Juho Hamari \\ Tampere University \\ juho.hamari@tuni.fi
}

Different kinds of media, usually audio or video media, can be delivered through streaming technology. Nowadays it is mostly applied by the entertainment industry for, e.g., leisure activities at home. It can be differentiated between on-demand streaming (e.g., YouTube, Netflix, Spotify), shortform video formats embedded in social media (e.g., TikTok, Snapchat or "Stories"-feature on Facebook or Instagram), and live streaming (e.g., Twitch, Taobao, YouTube Live) [1;2]. Some of these services make use of algorithms and recommender systems to propose media and content the user may be interested in and therefore lead to continued use of the system [3]. Ondemand streaming targets a consumption-oriented audience (with the focus on passive entertainment, such as streaming of TV shows on e.g., Netflix or music on e.g., Spotify), whereas live streaming offers user-generated content and participation between users, which can motivate more active social exchange [4], resulting in a special form of parasocial relationship, often found on services like Twitch [5]. Sometimes, digital gifts are presented as a form to strengthen these parasocial relationships, not seldom in monetary form [6]. User-generated streaming media presents a wide variety of content and categories, ranging from gaming-related videos [7], or Koreanstyle Mukbang (content creators eat food in front of the camera) [8], to beauty vloggers [9]. With the vast variety of content and platforms, several issues can be observed, including law infringements [10], or genderand sexuality-related harassment [11].

Since the first installment of the minitrack in 2019, popularity of the minitrack's topic increased, and for HICSS 2022, we received 11 submissions of which 5 papers were accepted for publication. The Streaming Media in Entertainment minitrack is proud to present the following papers.

One type of content genre on user-generated video streaming platforms are "foodshows." Foodshows are videos concentrating on topics related to eating and food - not only Mukbang, but also eating of a huge amount of food, cooking, and restaurant testing. Users who watch foodshows integrate them into their everyday life. Besides getting entertained, users are watching it while eating, before sleeping, and for emotional adjustment. The foodshow content watched was usually recommended by the algorithm of the video streaming system or uploaded by a followed channel [12].

A study by Gutzeit, Dorsch, and Stock [13] deals with giving, receiving, and following recommendations on video on-demand services. Users of video on-demand services get recommendations by the system at least once a week and only occasionally follow the system's recommendation - i.e., watching the recommended content. Furthermore, users give personal recommendations to and receive personal recommendations from other users (usually from friends, family, or acquaintances) several times a month. Personal recommendations are mostly given face-to-face and are followed more often than system based recommendations [13].

Regarding the research about parasocial relationships, on social live streaming services interpersonal relations and social actions play a special role. Social actions of streamers and viewers and their intention to continuous actions as well as shopping relations lead to stickiness towards individual streamers, streams, and services. The communication between streamers and their audience form a new kind of human-human relation, which is named cybersocial relation [14].

The popular eSports and gaming-related live streaming platform Twitch recently added an LGBTQIA+ tag to their system, which streamers can attach to their stream as some kind of content description. The LGBTQIA+ Twitch tag was implemented to make gender identity visible on the system and furthermore one step towards supporting, protecting, and promoting marginalized groups. Lopez and Freeman [15] found out that some users are grateful for making LGBTQIA+ visible on Twitch. However, the tag also fails to identify especially streamers who are LGBTQIA+ and some users even question why the LGBTQIA+ community needs their own tag. Furthermore, LGBTQIA+ streamers can be easily targeted and are not safe from harassment through this tag [15]. 
Music streaming services like, for example, Apple Music or Spotify make it possible for consumers to access millions of songs. In order to search for content and to find the right as well as similar soundtracks, it is a common practice to categorize songs into genres. However, the genres are not-standardized, arbitrary and, furthermore, similar genres often overlap. With the help of a data-driven approach, by representing artists in vector spaces, researchers generated high-density artist clusters to show context-based artist similarity. The analysis should provide insights about improvement of existing categories. The results show that especially the genres pop and rock are weak and need to be reconsidered. Furthermore, the genres jazz, techno, and reggae overlap [16].

\section{References}

[1] K.J. Fietkiewicz, J. Hamari, M. Törhönen, and F. Zimmer, "Introduction to the Minitrack on streaming media in entertainment”, Proceedings of the $54^{\text {th }}$ Hawaii International Conference on System Sciences (pp. 3077-3078). Honolulu, HI: HICSS (ScholarSpace), 2021.

[2] M. Törhönen, M. Sjöblom L. Hassan, and J. Hamari, "Fame and fortune, or just fun? A study on why people create content on video platforms", Internet Research, 30(1), 2019, pp. 165-190.

[3] K. Scheibe, K.J. Fietkiewicz, and W.G. Stock, "Information behavior on social live streaming services”, Journal of Information Science Theory and Practice, 4(2), 2016, pp. 6-20.

[4] M.R. Hasan, A.K. Jha, and Y. Liu, "Excessive use of online video streaming services: Impact of recommender system use, psychological factors, and motives”, Computers in Human Behavior, 40, 2018, pp. 220-228.

[5] A.P. Leith, "Parasocial cues: The ubiquity of parasocial relationships on Twitch", Communication Monographs, 88, 2021, pp. 111129.

[6] Y.-C. Lee, C.-H. Yen, D. Wang, and W.-T. Fu, "Understanding how digital gifting influences social interactions on live streams", in Proceedings of the 21st International Conference on Human-Computer Interaction with Mobile Devices and Services, 2019, ACM, New York, NY, art. no. 33, pp. 1-10.

[7] M. Sjöblom, M. Törhönen, J. Hamari, and J. Macey, "The ingredients of Twitch streaming: Affordances of game streams", Computers in Human Behavior, 92, 2019, pp. 20-28.

[8] L. Anjani, T. Mok, T. Tang, L. Oehlberg, and W. B. Goh,"Why do people watch others eat? an empirical study on the motivations and practices of mukbang viewers," in Proceedings of the 2020 CHI Conference on Human Factors in Computing Systems (CHI '20), ACM, 2020.

[9] R. Berryman and M. Kavka, “'I guess A lot of people see me as a big sister or a friend': the role of intimacy in the celebrification of beauty vloggers,” Journal of gender studies, vol. 26, no. 3, 2017, pp. 307-320.

[10] Fietkiewicz K.J. (2020) The law of live streaming: A systematic literature review and aAnalysis of German legal framework. In: Meiselwitz G. (eds) Social Computing and Social Media. Design, Ethics, User Behavior, and Social Network Analysis. HCII 2020. Lecture Notes in Computer Science, vol 12194. Springer, Cham. https://doi.org/10.1007/978-3-030-49570-1_16

[11] Twitch, "Introducing our new hateful conduct \& harassment policy," https://blog.twitch.tv/en/2020/12/09/introducingour-new-hateful-conduct-harassment-policy/, Dec. 2020.

[12] Z. Zhou, X. Ding, X. Tang, and Y. Cheng, “'I prefer an everyday style and dislike big food fighters': Integrating foodshow into everyday life", Proceedings of the 55th Hawaii International Conference on System Sciences (in press). Honolulu, HI: HICSS (ScholarSpace), 2022.

[13] J. Gutzeit, I. Dorsch, and W.G. Stock, "Giving and following recommendations on video-ondemand services", Proceedings of the 55th Hawaii International Conference on System Sciences (in press). Honolulu, HI: HICSS (ScholarSpace), 2022.

[14] K. Scheibe, F. Zimmer, K.J. Fietkiewicz, and W.G. Stock, "Interpersonal relations and social actions on live streaming services. A systematic review on cyber-social relations”, Proceedings of the 55th Hawaii International Conference on System Sciences (in press). Honolulu, HI: HICSS (ScholarSpace), 2022.

[15] J. Lopez and G. Freeman, “To tag or not to tag: The interplay of the Twitch tag system and LGBTQIA+ visibility in live streaming”, Proceedings of the 55th Hawaii International Conference on System Sciences (in press). Honolulu, HI: HICSS (ScholarSpace), 2022.

[16] C. Hotz-Behofsits, D. Winkler, and N. Wlömert, "Music genres reconsidered: Challenging established genres with a data-driven approach", Proceedings of the 55th Hawaii International Conference on System Sciences (in press). Honolulu, HI: HICSS (ScholarSpace), 2022. 